\title{
Possible role of microparticles in neuroimmune signaling of microglial cells
}

\author{
Stephanie M. Schindler ${ }^{1^{*}}$, Ekta Bajwa ${ }^{1^{*}}$, Jonathan P. Little ${ }^{2}$, Andis Klegeris ${ }^{1}$ \\ ${ }^{1}$ Department of Biology, University of British Columbia Okanagan Campus, Kelowna, British Columbia V1V 1 V7, Canada. \\ ${ }^{2}$ School of Health and Exercise Sciences, University of British Columbia Okanagan Campus, Kelowna, British Columbia V1V 1 V7, Canada. \\ *These authors contributed equally to this work.
}

Correspondence to: Dr. Andis Klegeris, Department of Biology, University of British Columbia Okanagan Campus, 3187 University Way, Kelowna, British Columbia V1V 1V7, Canada. E-mail: andis.klegeris@ubc.ca

How to cite this article: Schindler SM, Bajwa E, Little JP, Klegeris A. Possible role of microparticles in neuroimmune signaling of microglial cells. Neuroimmunol Neuroinflammation 2016;3:232-42.

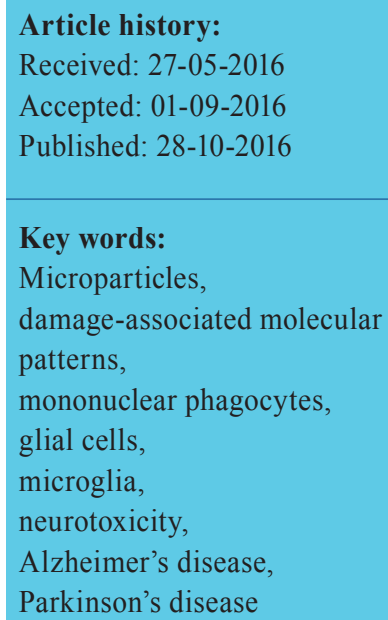

\section{Key words:}

Microparticles,

damage-associated molecular

patterns,

mononuclear phagocytes,

glial cells,

microglia,

neurotoxicity,

Alzheimer's disease,

Parkinson's disease

\section{ABSTRACT}

\section{INTRODUCTION}

Microglia are a distinct population of mononuclear phagocytes that represent the innate immune system in the brain..$^{[1]}$ Under physiological conditions, the phagocytic responses of microglia ensure proper functioning of neuronal cells as they remove harmful material and repair injured tissue. ${ }^{[2]}$ However, chronic activation of microglia, due to recognition of pathological
Aim: Submicron fragments termed microparticles (MPs), derived from all major central nervous system cell types including neurons and glia (microglia, astrocytes, oligodendrocytes), have emerged as novel intercellular signaling agents. This study tested the hypothesis that MPs derived from activated microglia, which represent the mononuclear phagocyte system in the brain, could induce pro-inflammatory and cytotoxic responses of microglia in an autocrine or paracrine manner. Methods: Human THP-1 monocytic cells were used to model human microglia. MPs derived from these cells were reapplied to THP-1 cells and their secretion of neurotoxins and cytokines was measured. Results: When exposed to lipopolysaccharide (LPS) or mitochondrial transcription factor A in combination with interferon (IFN)- $\gamma$, THP-1 cells released MPs. When reapplied to THP-1 cells, MPs induced the release of secretions that were toxic to human SH-SY5Y neuroblastoma cells, as well as monocyte chemoattractant protein-1. The cytotoxicity of THP-1 cells induced by MPs derived from IFN- $\gamma$ plus LPS-treated THP-1 donor cells was enhanced in the presence of IFN- $\gamma$. The MPs released by THP-1 cells were not directly toxic towards SH-SY5Y cells. Conclusion: Our data support the hypothesis that activated microglia-derived MPs could act as signaling agents that are recognized by microglia to cause pro-inflammatory and cytotoxic responses.

formations associated with central nervous system (CNS) disorders including the amyloid-beta $(A \beta)$ and a-synuclein aggregates observed in Alzheimer's and Parkinson's disease respectively can contribute to disease progression. ${ }^{[3,4]}$ The state of prolonged overactivation of microglia is characterized by increased secretion of pro-inflammatory cytokines as well as reactive oxygen and nitrogen species. ${ }^{[5-9]}$ Similar adverse activation of microglia occurs in response 
to other endogenous molecules such as damageassociated molecular patterns (DAMPs) released by damaged or dying cells. ${ }^{[10]}$ DAMPs identified in the CNS include the DNA-binding proteins high-mobility group box 1 (HMGB1) and mitochondrial transcription factor $A$ (TFAM). ${ }^{[11,12]}$

Recently, microparticles (MPs) have emerged as novel intercellular signaling agents, which can be released by all brain cell types. MP release from microglia is upregulated following their activation and such microliaderived MPs appear to possess immunomodulatory properties similar to HMGB1. ${ }^{[13-16]}$ Originally considered as inert platelet by-products, MPs are now known to be a heterogeneous population of membrane-derived vesicles ranging in diameter from 0.1 to $1 \mu \mathrm{m}$, which participate in intercellular signaling. ${ }^{[17,18]}$ The structural composition and content of MPs differs based on a variety of factors, including the cell type of origin and the nature of the inducing stimulus. ${ }^{[18]}$

As MPs can mediate intercellular communication, they have been implicated in the regulation of various physiological processes, including, cell proliferation, coagulation, and inflammation. ${ }^{[19]}$ Recent studies have also identified MP involvement in disease processes and the contribution of MPs to the progression of some neurodegenerative disorders has become increasingly evident. ${ }^{[20-24]}$ Elevated levels of MPs have been detected in the plasma and cerebrospinal fluid of individuals suffering from Alzheimer's disease, multiple sclerosis, and cerebral malaria. ${ }^{[20,25,26]}$

Upon activation by adenosine triphosphate, microglia and astrocytes have been found to release MPs carrying the pro-inflammatory cytokine interleukin (IL)-1 $\beta .^{[15,27]}$ Moreover, microglia-derived MPs have been shown to transfer inflammatory stimuli to other microglial cells, which then express pro-inflammatory genes such as IL-1 $\beta$ and IL-6. ${ }^{[28]}$ These findings suggest that inflammatory mediators may be liberated from glia-derived MPs and subsequently interact with surrounding cells, thus contributing to the neurotoxic environment observed in neuroinflammatory diseases. Therefore, elucidating MP involvement in glial cellmediated neuroinflammation may identify additional targets for the development of therapeutic strategies aimed at neuropathologies with neuroinflammatory components.

Although MP release by all major CNS cell types has been demonstrated, the role of MPs as mediators in glia-neuron communication remains to be fully characterized. ${ }^{[15,16,27]}$ Since MP release is upregulated upon activation and during apoptosis or necrosis; we hypothesized that MPs may act as endogenous
DAMPs with immunomodulatory properties similar to HMGB1 or TFAM. ${ }^{[15,29,30]}$ We demonstrated that human mononuclear phagocytes release MPs when activated by pro-inflammatory molecules. We also showed that THP-1 monocytic cell-derived MPs act in an autocrine or paracrine manner to induce secretions of pro-inflammatory cytokines and cytotoxins by these monocytic cells.

\section{METHODS}

\section{Reagents}

Sodium dodecyl sulphate (SDS), N,N-dimethylformamide (DMF), $0.05 \%$ trypsin with ethylenediaminetetraacetic acid (EDTA), fetal bovine serum (FBS), Dulbecco's modified Eagle medium: nutrient mixture F-12 Ham (DMEM/F12), penicillin/streptomycin stock solutions, bovine serum albumin (BSA), diethanolamine, and the Pierce bicinchoninic acid (BCA) Protein Assay Kit were purchased from ThermoFisher Scientific (Ottawa, ON, Canada). Dimethylsulfoxide (DMSO), lipopolysaccharide (LPS) from Escherichia coli O55:B5 and 3-(4,5-dimethyl-2-thiazolyl)-2,5-diphenyl2H-tetrazolium bromide (MTT) were purchased from Sigma-Aldrich (Oakville, ON, Canada). Human interferon (IFN)- $\gamma$ and enzyme-linked immunosorbent assay (ELISA) development kits for IL-6, tumor necrosis factor (TNF)- $\alpha$, and monocyte chemoattractant protein-1 (MCP-1) were purchased from Peprotech (Embrun, ON, Canada). The FITC Annexin-V Apoptosis Detection Kit was purchased from BD Biosciences (Mississauga, ON, Canada). Nanobead NIST traceable particle size standards were purchased from Polysciences Inc. (Warrington, PA, USA). Recombinant human TFAM was a gift from Dr. K. Wolthers (University of British Columbia Okanagan Campus, Kelowna, BC, Canada).

\section{Cell culture models}

The human monocytic THP-1 cell line was purchased from the American Type Culture Collection (ATCC, Manassas, VA, USA). The human neuroblastoma SHSY5Y cell line was donated by Dr. R. Ross (Department of Biological Sciences, Fordham University, Bronx, NY, USA). Cell cultures were grown in DMEM/F12 media containing $10 \%$ FBS, penicillin $(100 \mathrm{U} / \mathrm{mL})$ and streptomycin $(100 \mu \mathrm{g} / \mathrm{mL})$, and incubated at $37^{\circ} \mathrm{C}$ in humidified $5 \% \mathrm{CO}_{2}$ and $95 \%$ air atmosphere.

\section{MP isolation}

MPs were isolated using previously published protocols, which were modified as follows. ${ }^{[15,27,31]}$ Human monocytic THP-1 cells were counted using a hemocytometer, centrifuged for $7 \mathrm{~min}$ at $450 \mathrm{~g}$, and seeded into 12 -well plates at 0.5 million cells $/ \mathrm{mL}$ in 
DMEM/F12 with 5\% FBS. Following 30-min incubation, cells were stimulated by exposing them in duplicate wells to TFAM $(2.5 \mu \mathrm{g} / \mathrm{mL})$, IFN- $\gamma(150 \mathrm{U} / \mathrm{mL})$, IFN- $\gamma$ plus TFAM $(0.5 \mu \mathrm{g} / \mathrm{mL})$, IFN- $\gamma$ plus LPS $(0.5 \mu \mathrm{g} / \mathrm{mL})$, or vehicle solution (phosphate buffered saline, PBS). Following a 24-h incubation period, cultured supernatants from each well were collected into individual $50 \mathrm{~mL}$ centrifuge tubes and total cell numbers from each treatment were counted using a hemocytometer. A differential centrifugation procedure consisting of three steps was then performed at $4^{\circ} \mathrm{C}$ : (1) $5 \mathrm{~min}$ at $300 \mathrm{~g}$; (2) $20 \mathrm{~min}$ at $1,200 \mathrm{~g}$; (3) $30 \mathrm{~min}$ at $10,000 \mathrm{~g}$. After the first two centrifugation steps, the supernatants were collected and transferred into new $50 \mathrm{~mL}$ tubes. After the third step, however, the supernatants were discarded. The pellets were re-suspended in $1 \mathrm{~mL}$ of sterile PBS and the MP samples were washed by centrifugation for $30 \mathrm{~min}$ at $10,000 \mathrm{~g}$. The MP pellet was re-suspended in 1X Annexin- $V$ binding buffer from the FITC Annexin-V Apoptosis Detection Kit. The MP samples were stored at $-20^{\circ} \mathrm{C}$.

\section{MP detection and quantification \\ Flow cytometry}

To detect and quantify MPs released by THP-1 cells, the MP samples were analyzed using flow cytometry according to previously described methods. ${ }^{[32]}$ Briefly, $0.1 \mathrm{~mL}$ from each MP sample was combined with $5 \mu \mathrm{L}$ of Annexin-V-FITC stain and incubated at room temperature in the dark for $15 \mathrm{~min}$. Annexin- $V$ was used as it binds to the externalized phosphatidylserine on the surface of MPs. ${ }^{[33]}$ Following incubation, samples were centrifuged for $30 \mathrm{~min}$ at $10,000 \mathrm{~g}$ to remove any unbound Annexin-V-FITC. The MP pellet was resuspended in $0.1 \mathrm{~mL}$ of $1 \mathrm{X}$ Annexin- $\mathrm{V}$ binding buffer and analyzed using the MACSQuant Analyzer 10 with MACSQuantify software (Miltenyl Biotec). The MP size gate was defined using $0.5 \mu \mathrm{m}$ and $1.0 \mu \mathrm{m}$ calibration beads and events within the MP gate were further discriminated by Annexin- $V$ label. A logarithmic scale was used for side scatter, forward scatter, and fluorescence channels. MPs were identified as Annexin- $V$ positive events within the MP size gate with fluorescence intensity above a control sample not stained with Annexin-V-FITC.

\section{BCA protein assay}

Protein concentration in the MP samples was measured using the BCA protein assay as previously described. ${ }^{[34]}$ Briefly, $10 \mu \mathrm{L}$ of each MP sample were analyzed according to the instructions provided for the Pierce BCA Protein Assay Kit. BSA standards (0.0125$2 \mathrm{mg} / \mathrm{mL}$ ) prepared by diluting the BSA stock solution $(2 \mathrm{mg} / \mathrm{mL})$ in distilled water were used to construct a standard curve from which the protein concentration in the MP samples was calculated. MPs were used in experiments at a protein concentration of $10 \mu \mathrm{g} / \mathrm{mL}$.

Toxicity of MP-stimulated monocytic THP-1 cells towards neuronal SH-SY5Y cells

To study the cytotoxicity of monocytic THP-1 cells induced by MPs, supernatant transfer experiments were performed as previously described. ${ }^{[35]}$ Briefly, THP-1 cells were seeded into 96-well plates as $250 \mu \mathrm{L}$ aliquots at a concentration of 0.5 million cells $/ \mathrm{mL}$ in DMEM/F12 with 5\% FBS. Following 30 min incubation, THP-1 cells were stimulated with IFN- $\gamma(150 \mathrm{U} / \mathrm{mL})$, THP-1-derived MPs (10 $\mu \mathrm{g}$ protein $/ \mathrm{mL}), \mathrm{IFN}-\gamma$ plus THP-1-derived MPs, or left unstimulated by adding MP vehicle solution (1X Annexin-V binding buffer). After $48 \mathrm{~h}$ incubation, THP-1 cell supernatants were transferred onto SH-SY5Y cells seeded $24 \mathrm{~h}$ earlier into 96-well plates at 0.2 million cells $/ \mathrm{mL}$ in $200 \mu \mathrm{L}$ DMEM/F12 with $5 \%$ FBS. In addition, THP-1 cell supernatants were collected for IL-6, TNF- $\alpha$, and MCP-1 ELISA measurements. THP-1 cell viability was assessed using the MTT assay. SH-SY5Y cells were incubated for additional $72 \mathrm{~h}$ at which point an MTT assay was performed to assess their viability.

Direct toxicity of MPs derived from stimulated THP-1 cells towards neuronal SH-SY5Y cells

To determine whether the MPs isolated from stimulated human monocytic THP-1 cells were directly toxic to human neuronal SH-SY5Y cells, the following experiment was performed. Human neuronal SH-SY5Y cells were seeded into 24-well plates as $400 \mu \mathrm{L}$ aliquots per well at a concentration of 0.2 million cells $/ \mathrm{mL}$ in DMEM/F12 with 5\% FBS. Following 24-h incubation, SH-SY5Y cells were treated with MP vehicle solution (1XAnnexin-V binding buffer) or MPs (10 $\mu \mathrm{g}$ protein $/ \mathrm{mL}$ ) isolated from unstimulated THP-1 cells or THP-1 cells that had been stimulated with IFN- $\gamma$ in combination with LPS. Following 72-h incubation of SH-SY5Y cells with the MPs, the MTT assay was performed to assess neuronal cell viability.

\section{MTT cell viability assay}

Viability of the cells used during experiments was assessed using the MTT assay as previously described. ${ }^{[36,37]}$ This assay is based on the ability of viable cells to reduce the water-soluble tetrazolium dye MTT to an insoluble purple formazan product, which can be measured spectrophotometrically. MTT $(0.5 \mathrm{mg} / \mathrm{mL})$ was added to the wells containing cultured cells and the plates were incubated for $1 \mathrm{~h}$ at $37^{\circ} \mathrm{C}$. A $20 \%$ SDS $/ 50 \%$ DMF solution was then added at a 1:1 ratio to each well to solubilize the formazan crystals. After an additional incubation period of 3-4 $\mathrm{h}$ at $37^{\circ} \mathrm{C}, 0.1 \mathrm{~mL}$ aliquots from each well were transferred 
onto 96-well plates for optical density measurement at $570 \mathrm{~nm}$ using a microplate reader. The cell viability was expressed as a percent of the value obtained from cells treated with medium only.

\section{ELISA}

Concentrations of IL-6, TNF- $\alpha$, and MCP-1 in cell-free supernatants from THP-1 cells stimulated for $48 \mathrm{~h}$ with THP-1-derived MPs were measured using Peprotech ELISA development kits according to the manufacturer's instructions. The detection limits for the IL-6, TNF- $\alpha$, and MCP-1 ELISAs were experimentally determined to be $0.007 \mathrm{ng} / \mathrm{mL}, 0.09 \mathrm{ng} / \mathrm{mL}$, and $1.02 \mathrm{ng} / \mathrm{mL}$, respectively.

\section{Data analyses}

Statistical analyses of the data were conducted using SPSS software (version 22.0, IBM SPSS, Chicago IL, USA) and GraphPad PRISM software (version 6.0, GraphPad Software Inc, La Jolla CA, USA). Randomized blocks design analysis of variance (ANOVA) followed by Fisher's least-significant difference (LSD) post hoc test was used to determine significance of findings. Data are presented as means \pm standard error of the mean (S.E.M.). Statistical significance was considered at a $P$-value less than 0.05. Data from 3-11 independent experiments for each figure are presented.

\section{RESULTS}

\section{MP release by stimulated human monocytic THP-1 cells}

The ability of various stimuli to trigger MP release by monocytic THP-1 cells was investigated. THP-1 cells were stimulated for $24 \mathrm{~h}$ with IFN- $\gamma$ or a combination of IFN- $\gamma$ plus LPS, which has previously been shown to induce maximal stimulation of these cells. ${ }^{[38]}$ THP-1 cell supernatants were collected and MPs isolated using differential centrifugation. Representative scatter plots shown on Figure 1A-C illustrate that MPs were released by unstimulated and stimulated THP-1 cells as shown by the Annexin-V positive events within the MP size gate. The number of MPs released per million THP-1 cells was calculated. Figure 1D shows that significantly more MPs were released by THP-1 cells stimulated with a combination of IFN- $\gamma$ plus LPS compared to cells stimulated with IFN- $\gamma$ alone $(P=0.001)$ or unstimulated cells $(P=0.001)$.

Effects of THP-1 cell-derived MPs on THP-1 monocytic cell viability and their toxic secretions Next, we studied whether MPs derived from unstimulated and stimulated THP-1 cells induce cytotoxicity of THP-1 cells in a paracrine fashion. MPs derived from unstimulated THP-1 cells (control) or
THP-1 cells that had been stimulated with IFN- $\gamma$ alone or IFN- $\gamma$ plus LPS were added to THP-1 cell cultures. At the concentration tested, none of the isolated MPs significantly affected THP-1 cell viability [Figure 2A]. Cell-free supernatants from the THP-1 cells treated with different types of MPs were transferred onto SHSY5Y neuroblastoma cells to determine secretion of cytotoxins by MP-stimulated THP-1 cells [Figure 2B]. The MPs isolated from unstimulated THP-1 cells as well as those isolated from IFN- $\gamma$-stimulated THP-1 cells, did not induce THP-1 cell toxicity towards SH-SY5Y cells. However, the MPs isolated from THP-1 cells stimulated with IFN- $\gamma$ plus LPS induced cytotoxicity of THP-1 cells, resulting in a statistically significant decrease in viability of the neuronal cells compared to SH-SY5Y cells exposed to supernatants from unstimulated THP-1 cells $(P=0.013)$. The THP-1 cell toxicity induced by the MP population from IFN- $\gamma$ plus LPS-stimulated THP-1 donor cells was also significantly different from the effect of the supernatants from THP-1 cells stimulated with MPs isolated from unstimulated THP-1 donor cells $(P=0.001)$ and THP-1 cells stimulated with IFN- $\gamma$ alone $(P=0.048)$.

IF $\mathrm{N}-\gamma$ enhances THP-1 cell cytotoxicity induced by stimulated THP-1 cell-derived MPs

The synergistic effect of IFN- $\gamma$ and THP-1 cell-derived MPs on THP-1 cell cytotoxic secretions was also studied [Figure 3A]. The combination of IFN- $\gamma$ and IFN- $\gamma$ plus LPS-stimulated THP-1 cell-derived MPs was significantly toxic towards THP-1 cells compared to THP-1 cells treated with vehicle solution alone $(P=0.0001)$, IFN- $\gamma$ alone $(P=0.002)$, and MPs isolated from IFN- $\gamma$ plus LPS-stimulated THP-1 cells alone $(P=$ 0.0001). Supernatants from the differentially treated THP-1 cells were transferred onto SH-SY5Y cells and their viability was assessed after $72 \mathrm{~h}$ incubation. Figure 3B illustrates that the cytotoxicity of MPs derived from IFN- $\gamma$ plus LPS-stimulated THP-1 donor cells was enhanced by IFN- $\gamma$ being present during the incubation of THP-1 cells with these MPs.

MPs derived from TFAM plus IFN- $\gamma$-stimulated THP-1 cells induce cytotoxicity of THP-1 cells The ability of MPs derived from TFAM-stimulated monocytic THP-1 cells to induce cytotoxic secretions from THP-1 cells was also investigated. MTT assay showed no toxicity of the isolated MPs towards THP-1 cells at the concentration tested [Figure 4A]. Treatment of THP-1 cells with MPs isolated from TFAM-stimulated THP-1 donor cells did not cause secretion of cytotoxins by THP-1 cells. However, MPs from THP-1 cells stimulated with TFAM in combination with IFN- $\gamma$ induced THP-1 cell cytotoxicity resulting in a statistically significant decrease in SH-SY5Y cell viability compared 

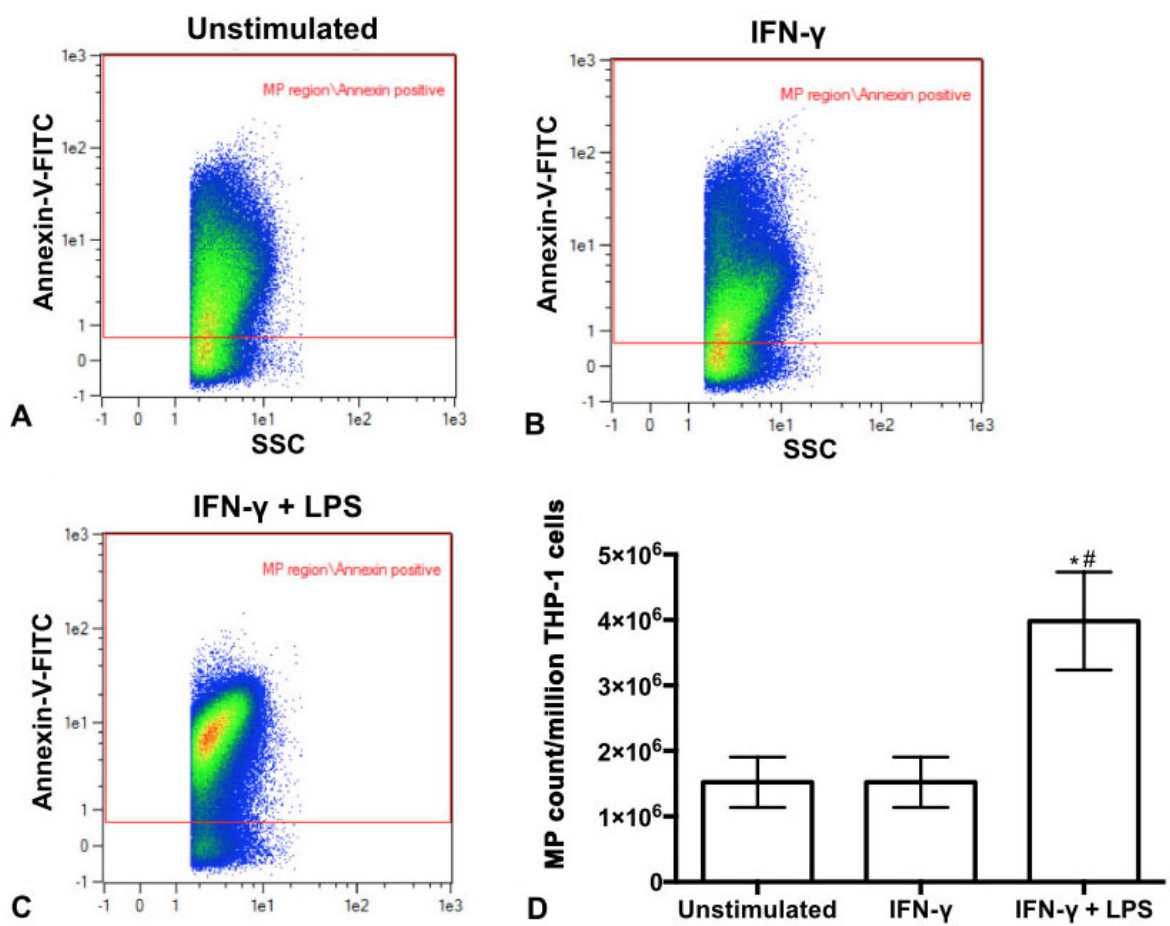

Figure 1: Flow cytometry scatter plots identify MPs released by human THP-1 monocytic cells that were unstimulated (A) or stimulated with IFN- $\gamma(B)$ or IFN- $\gamma$ plus LPS (C). Different colors reflect the density of MPs present, going from highest density (red) to lowest density (blue). The MP count per million THP-1 cells (D). ${ }^{*} P=0.001$ vs. unstimulated; ${ }^{*} P=0.001$ vs. IFN- $\gamma$. MPs: microparticles; LPS: lipopolysaccharide

to cells exposed to supernatants from unstimulated THP-1 cells $(P=0.01)$ as well as to SH-SY5Y cells exposed to supernatants from THP-1 cells treated with MPs from unstimulated THP-1 donor cells $(P=0.004)$ and THP- 1 cells stimulated with either IFN- $\gamma(P=0.011)$ or TFAM alone $(P=0.0001$, Figure $4 \mathrm{~B})$.

MPs derived from stimulated THP-1 cells are not directly toxic towards SH-SY5Y neuronal cells

To rule out the possibility that the effects on SH-SY5Y cell viability observed following their exposure to supernatants from MP-treated THP-1 cells might have been due to MPs that were transferred to SH-SY5Y cells with the supernatant, we performed a control experiment where SH-SY5Y cells were treated directly with MPs. MPs (10 $\mu \mathrm{g}$ protein $/ \mathrm{mL})$ isolated from THP-1 donor cells that had been stimulated with IFN- $\gamma$ plus LPS were incubated with SH-SY5Y cells for $72 \mathrm{~h}$. The MTT assay showed no direct toxicity of the isolated MPs towards SH-SY5Y cells at the concentration tested [Figure 5].
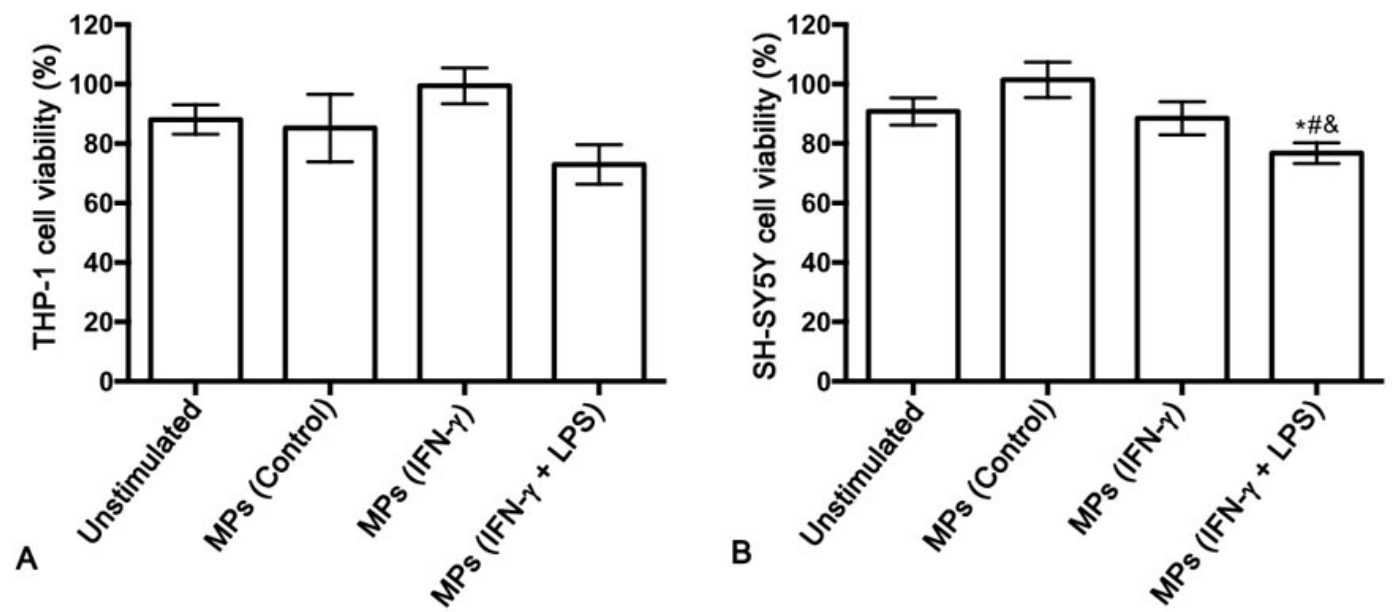

Figure 2: MPs isolated from IFN- $\gamma$ plus LPS-stimulated human monocytic THP-1 donor cells induce toxicity of THP-1 cells towards human neuronal SH-SY5Y cells. ${ }^{*} P=0.013$ vs. unstimulated; ${ }^{*} P=0.001$ vs. MPs (Control); ${ }^{\circledR} P=0.048$ vs. MPs (IFN- $\gamma$ ). LPS: lipopolysaccharide 

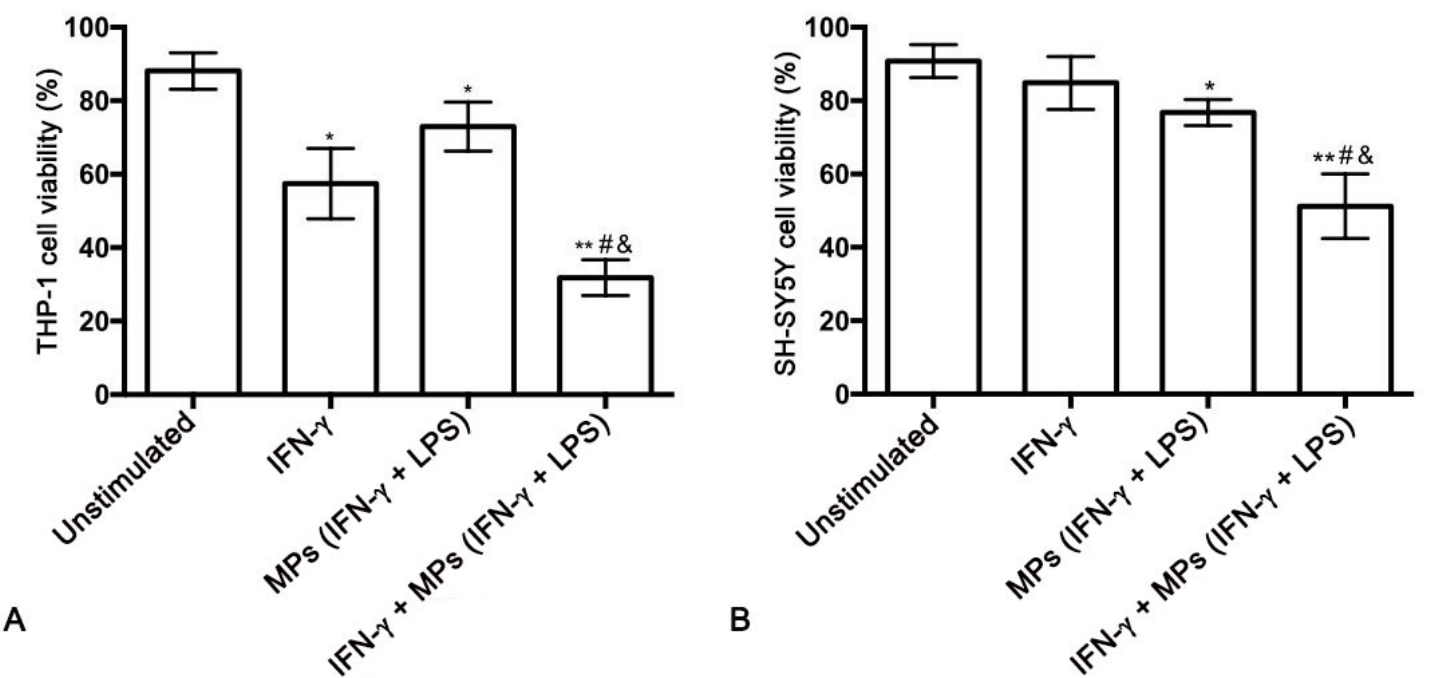

Figure 3: IFN- $\gamma$ enhances cytotoxicity of monocytic THP-1 cells induced by stimulated THP-1 cell-derived MPs. ${ }^{*} P=0.034,0.028(\mathrm{~A}){ }^{*} P=0.021$ (B) ${ }^{\star *} P=0.0001$ (AB) vs. unstimulated; ${ }^{\#} P=0.002$ (A) ${ }^{\#} P=0.004$ (B) vs. IFN- $\gamma ;{ }^{\&} P=0.0001(\mathrm{~A}){ }^{\&} P=0.007$ (B) $v s$. MPs (IFN- $\left.\gamma+\mathrm{LPS}\right)$. MPS: microparticles

Effects of MPs on cytokine secretion by THP-1 monocytic cells

Concentrations of the pro-inflammatory cytokines TNF- $\alpha$, IL-6, and MCP-1 were measured in the cell-free supernatants from THP-1 cells exposed to MPs derived from THP-1 cells treated with different stimuli. None of the MPs tested induced the secretion of TNF- $\alpha$ or IL- 6 by THP- 1 cells regardless of the type of stimulation the MP donor THP-1 cells received (data not shown). The secretion of MCP-1 was significantly enhanced in THP-1 cells treated with MPs isolated from IFN- $\gamma$ plus LPS-stimulated donor THP-1 cells compared to the THP-1 cells treated with vehicle solution only (unstimulated) $(P$ $=0.004$, Figure 6).

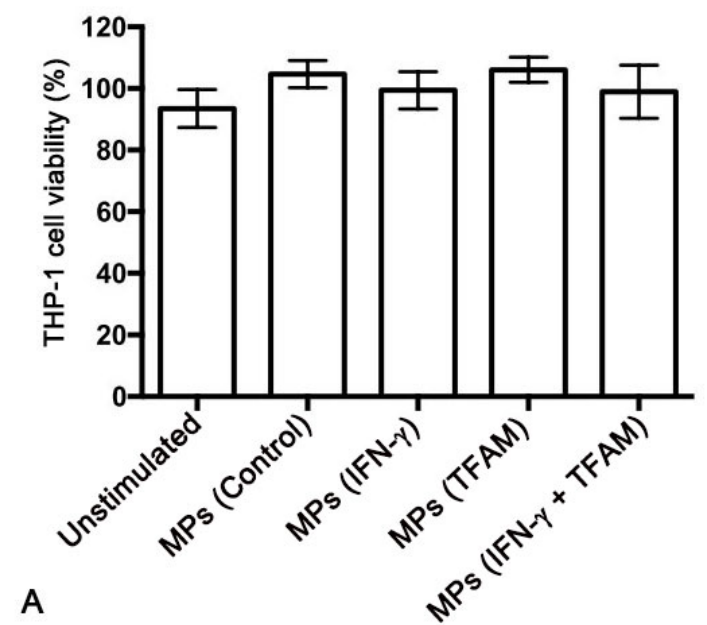

\section{DISCUSSION}

There is increasing evidence that MPs are novel intercellular signaling agents that can be released by a variety of CNS cell types including microglia. MPs may exhibit immunomodulatory and biological properties similar to DAMPs, such as HMGB1 and TFAM. ${ }^{[13-16]}$ Several studies have investigated the role of MPs as mediators of astrocyte-neuron communication; ${ }^{[15,16,27]}$ however, to date the role of MPs as mediators in microglia communication with neurons, astrocytes, and other microglia remains less characterized.

The MP release and neurotoxicity assays employed in this study used human monocytic THP-1 cells and the SH-SY5Y human neuroblastoma cell line,

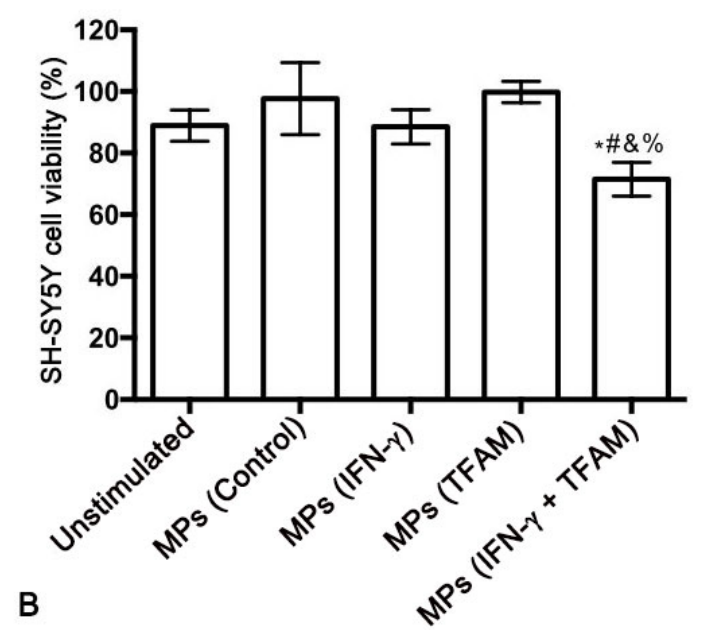

Figure 4: MPs isolated from human monocytic THP-1 donor cells stimulated with TFAM in combination with IFN- $\gamma$ induce cytotoxicity of THP-1 cells towards human SH-SY5Y neuronal cells. ${ }^{\star} P=0.01$ vs. unstimulated; ${ }^{*} P=0.004$ vs. MPs (Control); ${ }^{\&} P=0.011$ vs. MPs (IFN- $\gamma$ ); ${ }^{\%} P=0.0001$ vs. MPs (TFAM). MPs: microparticles; TFAM: mitochondrial transcription factor A 


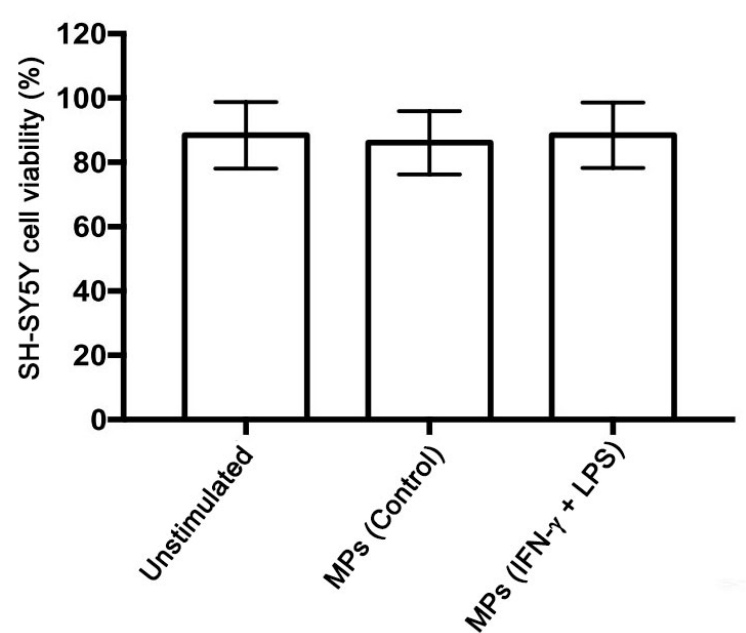

Figure 5: MPs isolated from IFN- $\gamma$ plus LPS-stimulated human monocytic THP-1 donor cells are not directly toxic to human neuronal SH-SY5Y cells. MPs: microparticles; LPS: lipopolysaccharide

which have been widely used to model human macrophages (including microglia) and human neurons, respectively. ${ }^{[38-43]}$ Moreover, the neurotoxicity induced by THP-1 cells in these experiments has been demonstrated to be very similar to that of human microglia derived from post mortem brain tissues. ${ }^{[4]}$ Additionally, Combs et al. ${ }^{[45]}$ showed that stimulated primary murine microglia cause toxicity toward mouse embryonic neurons in a manner very similar to the actions of stimulated THP-1 cells. Activation of THP-1 cells characterized by upregulated proinflammatory cytokine and cytotoxin secretion resulting in significantly reduced survival of SH-SY5Y cells has been achieved previously by stimulation with several

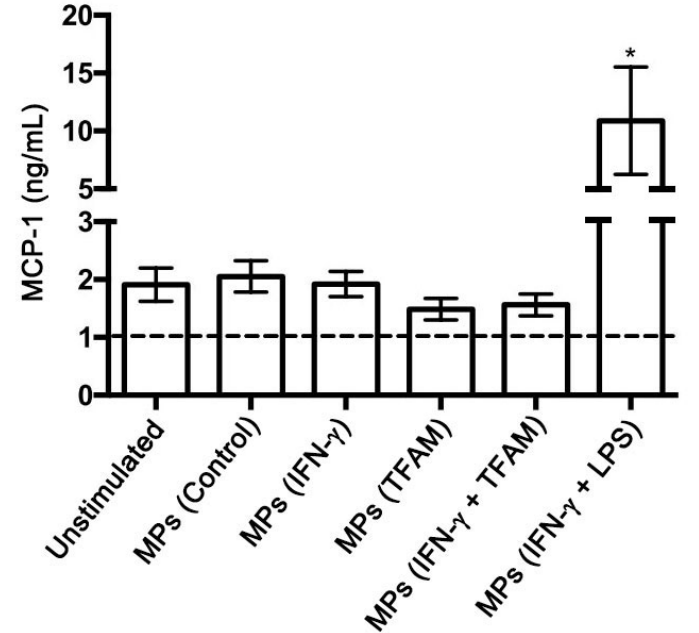

Figure 6: MPs isolated from IFN- $\gamma$ plus LPS-stimulated THP-1 donor cells increase MCP-1 secretion by THP-1 cells. ${ }^{*} P=0.004$ vs. unstimulated. MPs: microparticles; LPS: lipopolysaccharide

different combinations of cytokines and inflammatory mediators including IFN- $\gamma$ and LPS. ${ }^{[38,44,46]}$ Our previous studies show that high concentrations of LPS (such as $0.5 \mu \mathrm{g} / \mathrm{mL}$ used in this study) in combination with IFN- $\gamma$ induce maximum activation of THP-1 cells; however lower concentrations of LPS (e.g. $0.5 \mathrm{ng} / \mathrm{mL}$ ) can also be used. ${ }^{[47,48]}$

First, to confirm that MPs could be released by our model of activated microglia, IFN- $\gamma$ alone or in combination with LPS was added to human THP-1 monocytic cells for $24 \mathrm{~h}$. Following incubation, the released MPs were isolated by differential centrifugation and analyzed by flow cytometry. Both unstimulated and stimulated

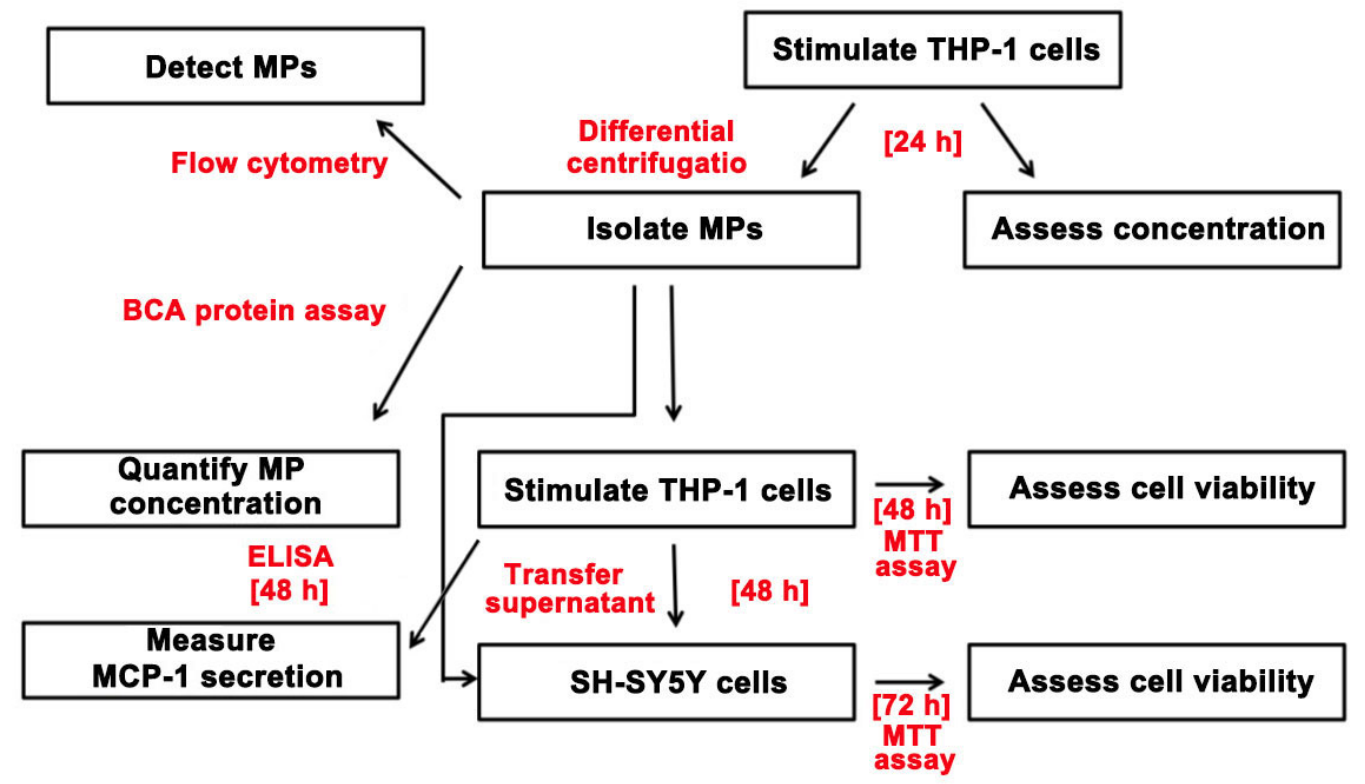

Figure 7: Flow diagram of the experimental procedure utilized in this study to determine whether MPs derived from THP-1 donor cells induce THP-1 cell neurotoxicity and cytokine secretion in an autocrine or paracrine manner. MPs: microparticles 
THP-1 cells released MPs. This is consistent with previous publications showing the constitutive release of MPs by resting cells. ${ }^{[29,49]}$ LPS in combination with IFN- $\gamma$ was the only combination from the stimulants tested to induce the release of MPs above the levels released by the unstimulated control cells. This observation correlates well with other studies showing that activation can significantly upregulate MP release by a variety of cell types, including THP-1 cells..$^{[15,27]}$ It is important to note that IFN- $\gamma$ on its own did not enhance the release of MPs, which is consistent with previous studies demonstrating that IFN- $\gamma$ is not capable of inducing significant monocytic cell cytotoxicity in the absence of additional co-stimulatory molecule(s). ${ }^{[38,43]}$

Next, we investigated whether the isolated MPs possessed cytotoxic properties by conducting supernatant transfer experiments, which involved exposing THP- 1 cells to MPs (10 $\mu \mathrm{g}$ protein $/ \mathrm{mL}$ ) isolated from THP-1 cells that had been stimulated with IFN- $\gamma$ alone or in combination with LPS for $48 \mathrm{~h}$. Our data indicate that MPs derived from IFN- $\gamma$ plus LPS-stimulated THP-1 cells possess the ability to induce monocytic cell toxicity, while MPs derived from cells stimulated with IFN- $\gamma$ only lack this ability. The cytotoxicity of THP-1 cells induced by MPs derived from IFN- $\gamma$ plus LPS-stimulated THP-1 donor cells was enhanced by co-stimulation with IFN- $\gamma$. This finding was expected, as IFN- $\gamma$ is a critical regulatory molecule involved in both innate and acquired immunity that has been shown to modulate the immune response of phagocytic cells. ${ }^{[50]}$ Stimulation with IFN- $\gamma$ on its own did not induce monocytic cell toxicity towards neuronal cells, reinforcing the idea that IFN- $\gamma$ requires additional co-stimulatory molecules to achieve significant monocytic cell activation and secretion of cytotoxins. Since only the MTT assay was performed on SH-SY5Y cells, it is not known whether the neuronal cell death induced by supernatants from MP-stimulated THP-1 cells involved mainly apoptotic or necrotic mechanisms. Further studies are needed to address this research question. We also confirmed that the cytotoxic activity of the IFN- $\gamma$ plus LPS-derived MPs towards the neuronal cells was indirect, as direct exposure of SH-SY5Y cells to MPs derived from either unstimulated or stimulated THP-1 cells did not induce any toxic effects [Figure 7].

Further studies will be required to determine the molecular content of the MPs isolated in these experiments and the mechanism of action of these MPs including the receptors involved in inducing the observed THP-1 cell toxicity towards the SHSY5Y neuronal cells. A number of studies have shown that activated cells shed MPs containing inflammatory mediators such as IL-1 $\beta$, which, in turn, is released to activate other immune cells and trigger an inflammatory response. ${ }^{[15]}$ Our data demonstrate that the monocytic cell-derived MPs are able to act in an autocrine or paracrine manner. By recruiting additional monocytes, this activation pattern may then contribute to perpetuating the inflammation present in neuroinflammatory diseases such as Alzheimer's disease. Peroxisome proliferator-activated receptor gamma (PPAR- $\gamma$ ) has been shown to be one of the receptors targeted by MPs during autocrine activation of monocytes. ${ }^{\left[{ }^{11}\right]}$ Identifying the receptors mediating the cellular effects of MPs may provide additional targets for attenuating the induced neuroinflammation.

TFAM, a novel DAMP, activates three different types of cultured human mononuclear phagocytes, including THP-1 cells, peripheral blood monocytes, and primary human microglia. It induces the expression of the pro-inflammatory cytokines IL-1 $\beta$, IL-6, and IL-8. ${ }^{[12]}$ Therefore, we decided to investigate an additional mechanism of action of TFAM by elucidating the role of MPs in TFAM-induced microglial toxicity towards neuronal cells. Moreover, to our knowledge, the role of DAMPs such as TFAM or HMGB1 as triggers of MP release has not yet been investigated. Similar to the results obtained for the IFN- $\gamma$ plus LPS-derived MPs, the MPs derived from donor THP-1 cells stimulated with TFAM plus IFN- $\gamma$ induced toxicity of THP-1 cells towards the SH-SY5Y neuronal cells, resulting in decreased cell viability.

MPs were also investigated for their ability to induce the release of pro-inflammatory cytokines by THP-1 cells. Only MPs derived from IFN- $\gamma$ plus LPS-stimulated THP-1 cells induced the release of MCP-1 above the levels of the unstimulated control cells. MCP-1 is a potent chemotactic factor for innate immune cells that is produced by a variety of cell types including monocytes, astrocytes, and microglial cells, either constitutively or following activation by pro-inflammatory cytokines and oxidative stress. ${ }^{\left[{ }^{[2]}\right]}$ Within the CNS, MCP-1 has been shown to facilitate the infiltration of peripheral blood monocytes across the blood-brain barrier and thereby amplify the neuroinflammatory state observed in neuropathologies with dysregulated microglial activation. ${ }^{[53]}$ The CNS neurotoxicity associated with inflammatory mediators is often due to their action on microglia and astrocytes that leads to the secretion of reactive oxygen species or cytotoxins such as TNF- $\alpha$. These mediators, in turn, can induce apoptotic or necrotic cell death of nearby neurons. ${ }^{[54-57]}$ Yang et al. ${ }^{[58]}$ showed that MCP-1 was not toxic towards cultures of primary cortical neurons. In the presence of microglia, however, MCP-1 was shown to cause neuronal death. Microglia express receptors for MCP-1, and MCP-1 was found to 
increase microglial mRNA expression of TNF- $\alpha$ and IL$1 \beta$. Use of an MCP-1 neutralizing antibody decreased MCP-1 induced upregulated microglial expression of these pro-inflammatory mediators and also attenuated MCP-1 induced neuronal death in neuron/microglia cocultures ${ }^{[58]}$ Accordingly, these properties of MCP-1 may provide an explanation for MP-mediated THP-1 cell toxicity towards SH-SY5Y neuronal cells.

MPs did not induce release of IL-6 and TNF- $\alpha$ (data not shown). These observations differ from results showing the release of IL-6 and TNF- $\alpha$ by human monocytes treated with MPs isolated from human monocytes stimulated with calcium ionophore A23187..59] This study also demonstrated that the MPs induced nuclear factor- $\kappa B$ activation, which would explain the observed secretion of these pro-inflammatory cytokines. It is important to note that there are several factors that may influence the concentration and the type of MPs produced in vitro including: (1) the donor cell type; ${ }^{[60,61]}(2)$ the stimulating agent used; ${ }^{[62]}$ and (3) the incubation time with the stimulant. ${ }^{[63]}$ These factors can modify the structure and content of the MPs released, thus affecting the physiological function of the MPs generated, leading to a different response elicited from the target cell. Therefore, additional experiments are required to fully characterize the MPs isolated in our experiment, to obtain a better understanding of the role that MPs play in microglia communication with other CNS cells.

Taken together, our data support previous observations that MPs could serve as intercellular signaling molecules in the brain. Since MPs can be released by a variety of activated cells, including microglia, and induce the release of additional inflammatory mediators from surrounding cells, they can perpetuate the inflammatory and neurotoxic environment observed in neuroinflammatory diseases. Therefore, further elucidation of the receptors and signaling pathways involved in MP-induced microglial cell activation is warranted as it may lead to the identification of additional targets for the development of therapeutic strategies aimed at preventing or treating the neuroinflammatory component characteristic of several CNS disorders.

\section{Financial support and sponsorship}

This work was supported by grants from the Jack Brown and Family Alzheimer's Disease Research Foundation, the Natural Sciences and Engineering Research Council of Canada, and the University of British Columbia Okanagan Campus.

\section{Conflict of interest}

There are no conflicts of interest.

\section{Patient consent}

No patients involved.

\section{Ethics approval}

This article does not contain any studies with human participants or animals.

\section{REFERENCES}

1. Solito E, Sastre M. Microglia function in Alzheimer's disease. Front Pharmacol 2012;3:14

2. Cai Z, Hussain MD, Yan LJ. Microglia, neuroinflammation, and betaamyloid protein in Alzheimer's disease. Int J Neurosci 2014;124:307-21.

3. Eikelenboom P, Hoozemans JJ, Veerhuis R, van Exel E, Rozemuller AJ, van Gool WA. Whether, when and how chronic inflammation increases the risk of developing late-onset Alzheimer's disease. Alzheimers Res Ther 2012;4:15.

4. Kettenmann H, Hanisch UK, Noda M, Verkhratsky A. Physiology of microglia. Physiol Rev 2011;91:461-553.

5. Zhang J, Malik A, Choi HB, Ko RW, Dissing-Olesen L, MacVicar BA. Microglial CR3 activation triggers long-term synaptic depression in the hippocampus via NADPH oxidase. Neuron 2014;82:195-207.

6. Moss DW, Bates TE. Activation of murine microglial cell lines by lipopolysaccharide and interferon-gamma causes NO-mediated decreases in mitochondrial and cellular function. Eur $J$ Neurosci 2001;13:529-38

7. Dheen ST, Jun Y, Yan Z, Tay SS, Ling EA. Retinoic acid inhibits expression of TNF-alpha and iNOS in activated rat microglia. Glia 2005;50:21-31.

8. Ferrari D, Chiozzi P, Falzoni S, Hanau S, Di Virgilio F. Purinergic modulation of interleukin-1 beta release from microglial cells stimulated with bacterial endotoxin. J Exp Med 1997;185:579-82.

9. Garcao P, Oliveira CR, Agostinho P. Comparative study of microglia activation induced by amyloid-beta and prion peptides: role in neurodegeneration. J Neurosci Res 2006;84:182-93.

10. Thundyil J, Lim KL. DAMPs and neurodegeneration. Ageing Res Rev 2015;24:17-28.

11. Gao HM, Zhou H, Zhang F, Wilson BC, Kam W, Hong JS. HMGB1 acts on microglia Mac1 to mediate chronic neuroinflammation that drives progressive neurodegeneration. J Neurosci 2011;31:1081-92.

12. Little JP, Simtchouk S, Schindler SM, Villanueva EB, Gill NE, Walker DG, Wolthers KR, Klegeris A. Mitochondrial transcription factor A (Tfam) is a pro-inflammatory extracellular signaling molecule recognized by brain microglia. Mol Cell Neurosci 2014;60:88-96.

13. Ardoin SP, Pisetsky DS. The role of cell death in the pathogenesis of autoimmune disease: HMGB1 and microparticles as intercellular mediators of inflammation. Mod Rheumatol 2008;18:319-26.

14. Pisetsky DS, Gauley J, Ullal AJ. HMGB1 and microparticles as mediators of the immune response to cell death. Antioxid Redox Signal 2011;15:2209-19.

15. Bianco F, Pravettoni E, Colombo A, Schenk U, Möller T, Matteoli M, Verderio C. Astrocyte-derived ATP induces vesicle shedding and IL-1 beta release from microglia. J Immunol 2005; 174:7268-77.

16. Colombo E, Borgiani B, Verderio C, Furlan R. Microvesicles: novel biomarkers for neurological disorders. Front Physiol 2012;3:63.

17. Wolf $P$. The nature and significance of platelet products in human plasma. Br J Haematol 1967;13:269-88.

18. Barteneva NS, Fasler-Kan E, Bernimoulin M, Stern JN, Ponomarev ED, Duckett L, Vorobjev IA. Circulating microparticles: square the circle. BMC Cell Biol 2013;14:23.

19. Gyorgy B, Szabó TG, Pásztói M, Pál Z, Misják P, Aradi B, László V, Pállinger E, Pap E, Kittel A, Nagy G, Falus A, Buzás EI. Membrane 
vesicles, current state-of-the-art: emerging role of extracellular vesicles. Cell Mol Life Sci 2011;68:2667-88.

20. Saman S, Kim W, Raya M, Visnick Y, Miro S, Saman S, Jackson B, McKee AC, Alvarez VE, Lee NC, Hall GF. Exosome-associated tau is secreted in tauopathy models and is selectively phosphorylated in cerebrospinal fluid in early Alzheimer disease. $J$ Biol Chem 2012;287:3842-9.

21. Schindler SM, Little JP, Klegeris A. Microparticles: a new perspective in central nervous system disorders. Biomed Res Int 2014:756327.

22. Tramontano AF, Lyubarova R, Tsiakos J, Palaia T, Deleon JR, Ragolia L. Circulating endothelial microparticles in diabetes mellitus. Mediators Inflamm 2010:250476.

23. Wang JG, Geddings JE, Aleman MM, Cardenas JC, Chantrathammachart P, Williams JC, Kirchhofer D, Bogdanov VY, Bach RR, Rak J, Church FC, Wolberg AS, Pawlinski R, Key NS, Yeh JJ, Mackman N. Tumor-derived tissue factor activates coagulation and enhances thrombosis in a mouse xenograft model of human pancreatic cancer. Blood 2012;119:5543-52.

24. Horstman LL, Jy W, Minagar A, Bidot CJ, Jimenez JJ, Alexander JS, Ahn YS. Cell-derived microparticles and exosomes in neuroinflammatory disorders. Int Rev Neurobiol 2007;79:227-68.

25. Minagar A, Jy W, Jimenez JJ, Sheremata WA, Mauro LM, Mao WW, Horstman LL, Ahn YS. Elevated plasma endothelial microparticles in multiple sclerosis. Neurology 2001;56:1319-24.

26. Combes V, Coltel N, Alibert M, van Eck M, Raymond C, JuhanVague I, Grau GE, Chimini G. ABCA1 gene deletion protects against cerebral malaria: potential pathogenic role of microparticles in neuropathology. Am J Pathol 2005;166:295-302.

27. Bianco F, Perrotta C, Novellino L, Francolini M, Riganti L, Menna E, Saglietti L, Schuchman EH, Furlan R, Clementi E, Matteoli M, Verderio C. Acid sphingomyelinase activity triggers microparticle release from glial cells. EMBO J 2009;28:1043-54.

28. Verderio C, Muzio L, Turola E, Bergami A, Novellino L, Ruffini F, Riganti L, Corradini I, Francolini M, Garzetti L, Maiorino C, Servida F, Vercelli A, Rocca M, Dalla Libera D, Martinelli V, Comi G, Martino G, Matteoli M, Furlan R. Myeloid microvesicles are a marker and therapeutic target for neuroinflammation. Ann Neurol 2012;72:610-24.

29. Distler JH, Huber LC, Hueber AJ, Reich CF 3rd, Gay S, Distler O, Pisetsky DS. The release of microparticles by apoptotic cells and their effects on macrophages. Apoptosis 2005;10:731-41.

30. Pisetsky DS. The expression of HMGB1 on microparticles released during cell activation and cell death in vitro and in vivo. Mol Med 2014;20:158-63.

31. Antonucci F, Turola E, Riganti L, Caleo M, Gabrielli M, Perrotta C, Novellino L, Clementi E, Giussani P, Viani P, Matteoli M, Verderio C. Microvesicles released from microglia stimulate synaptic activity via enhanced sphingolipid metabolism. EMBO J 2012;31:1231-40.

32. Dey-Hazra E, Hertel B, Kirsch T, Woywodt A, Lovric S, Haller H, Haubitz M, Erdbruegger U. Detection of circulating microparticles by flow cytometry: influence of centrifugation, filtration of buffer, and freezing. Vasc Health Risk Manag 2010;6:1125-33.

33. Connor DE, Exner T, Ma DD, Joseph JE. Detection of the procoagulant activity of microparticle-associated phosphatidylserine using XACT. Blood Coagul Fibrinolysis 2009;20:558-64.

34. Sorensen K, Brodbeck U. A sensitive protein assay method using micro-titer plates. Experientia 1986;42:161-2.

35. Klegeris A, Bissonnette CJ, McGeer PL. Reduction of human monocytic cell neurotoxicity and cytokine secretion by ligands of the cannabinoid-type CB2 receptor. Br J Pharmacol 2003;139:775-86.

36. Mosmann T. Rapid colorimetric assay for cellular growth and survival: application to proliferation and cytotoxicity assays. J Immunol Methods 1983;65:55-63.

37. Hansen MB, Nielsen SE, Berg K. Re-examination and further development of a precise and rapid dye method for measuring cell growth/cell kill. J Immunol Methods 1989;119:203-10.

38. Klegeris A, Bissonnette CJ, McGeer PL. Modulation of human microglia and THP-1 cell toxicity by cytokines endogenous to the nervous system. Neurobiol Aging 2005;26:673-82.

39. Hsu HY, Nicholson AC, Hajjar DP. Inhibition of macrophage scavenge receptor activity by tumor necrosis factor-alpha is transcriptionally and post-transcriptionally regulated. J Biol Chem 1996;271:7767-73.

40. Prieto J, Eklund A, Patarroyo M. Regulated expression of integrins and other adhesion molecules during differentiation of monocytes into macrophages. Cell Immunol 1994;156:191-211.

41. Soncin F, Calderwood SK. Reciprocal effects of pro-inflammatory stimuli and anti-inflammatory drugs on the activity of heat shock factor-1 in human monocytes. Biochem Biophys Res Commun 1996;229:479-84

42. Tsuchiya S, Kobayashi Y, Goto Y, Okumura H, Nakae S, Konno $\mathrm{T}$, Tada K. Induction of maturation in cultured human monocytic leukemia cells by a phorbol diester. Cancer Res 1982;42:1530-6.

43. Klegeris A, Pelech S, Giasson BI, Maguire J, Zhang H, McGeer EG, McGeer PL. Alpha-synuclein activates stress signaling protein kinases in THP-1 cells and microglia. Neurobiol Aging 2008;29:739-52.

44. Klegeris A \& McGeer PL. Interaction of various intracellular signaling mechanisms involved in mononuclear phagocyte toxicity toward neuronal cells. J Leukoc Biol 2000;67:127-33.

45. Combs CK, Johnson DE, Cannady SB, Lehman TM, Landreth GE. Identification of microglial signal transduction pathways mediating a neurotoxic response to amyloidogenic fragments of beta-amyloid and prion proteins. J Neurosci 1999;19:928-39.

46. Klegeris A, McGeer PL. Inflammatory cytokine levels are influenced by interactions between THP-1 monocytic, U-373 MG astrocytic, and SH-SY5Y neuronal cell lines of human origin. Neurosci Lett 2001;313:41-4.

47. Wang JG, Williams JC, Davis BK, Jacobson K, Doerschuk CM, Ting JP, Mackman N. Monocytic microparticles activate endothelial cells in an IL-1beta-dependent manner. Blood 2011;118:2366-74

48. Ehsan M, Lovren F, Quan A, Verma S. Adiponectin limits monocyticmicroparticle-inducedinflammasomeactivation andendothelialdysfunction. Can J Cardiology 2014;30:S284-5.

49. Cocucci E, Racchetti G, Meldolesi J. Shedding microvesicles: artefacts no more. Trends Cell Biol 2009;19:43-51.

50. Saha B, Jyothi Prasanna S, Chandrasekar B, Nandi D. Gene modulation and immunoregulatory roles of interferon gamma. Cytokine 2010;50:1-14.

51. Bardelli C, Amoruso A, Federici Canova D, Fresu L, Balbo P, Neri T, Celi A, Brunelleschi S. Autocrine activation of human monocyte/ macrophages by monocyte-derived microparticles and modulation by PPARgamma ligands. Br J Pharmacol 2012;165:716-28.

52. Deshmane SL, Kremlev S, Amini S, Sawaya BE. Monocyte chemoattractant protein-1 (MCP-1): an overview. $J$ Interferon Cytokine Res 2009;29:313-26.

53. Kremlev SG, Roberts RL, Palmer C. Differential expression of chemokines and chemokine receptors during microglial activation and inhibition. J Neuroimmunol 2004;149:1-9.

54. Thornton P, Pinteaux E, Gibson RM, Allan SM, Rothwell NJ. Interleukin1 -induced neurotoxicity is mediated by glia and requires caspase activation and free radical release. $J$ Neurochem 2006;98:258-66.

55. Takeuchi H, Jin S, Wang J, Zhang G, Kawanokuchi J, Kuno R, Sonobe Y, Mizuno T, Suzumura A. Tumor necrosis factor-alpha induces neurotoxicity via glutamate release from hemichannels of activated microglia in an autocrine manner. J Biol Chem 2006;281:21362-8.

56. Brown GC. Nitric oxide and neuronal death. Nitric Oxide 2010;23:153-65.

57. Hu S, Peterson PK, Chao CC. Cytokine-mediated neuronal apoptosis. Neurochem Int 1997;30:427-31. 
58. Yang G, Meng Y, Li W, Yong Y, Fan Z, Ding H, Wei Y, Luo J, Ke ZJ. Neuronal MCP-1 mediates microglia recruitment and neurodegeneration induced by the mild impairment of oxidative metabolism. Brain Pathol 2011;21:279-97.

59. Bardelli C, Gunella G, Varsaldi F, Balbo P, Del Boca E, Bernardone IS, Amoruso A, Brunelleschi S. Expression of functional NK1 receptors in human alveolar macrophages: superoxide anion production, cytokine release and involvement of NF-kappaB pathway. $\mathrm{Br} J$ Pharmacol 2005; 145:385-96.

60. Cerri C, Chimenti D, Conti I, Neri T, Paggiaro P, Celi A. Monocyte/ macrophage-derived microparticles up-regulate inflammatory mediator synthesis by human airway epithelial cells. J Immunol
2006; 177:1975-80.

61. Li M, Yu D, Williams KJ, Liu ML. Tobacco smoke induces the generation of procoagulant microvesicles from human monocytes/ macrophages. Arterioscler Thromb Vasc Biol 2010;30:1818-24.

62. Bernimoulin M, Waters EK, Foy M, Steele BM, Sullivan M, Falet H, Walsh MT, Barteneva N, Geng JG, Hartwig JH, Maguire PB, Wagner DD. Differential stimulation of monocytic cells results in distinct populations of microparticles. J Thromb Haemost 2009;7:1019-28.

63. Gauley J, Pisetsky DS. The release of microparticles by RAW 264.7 macrophage cells stimulated with TLR ligands. J Leukoc Biol 2010;87:1115-23 